\title{
Neuroendocrine activation after myocardial infarction
}

\author{
Jouko Remes
}

An acute myocardial infarction causes a threat to circulatory homoeostasis, and the activation of various neuroendocrine systems is believed to be an attempt to readjust to both myocardial and systemic consequences of the destabilising event. Increased sympathetic nervous tone, enhanced activity of the circulating and local renin-angiotensin systems, and disturbed endocrine or paracrine function of the endothelium may all provoke vasoconstriction in the systemic and coronary vascular beds. Activation of the reninangiotensin system also serves to induce salt and water retention and to expand circulating blood volume. On the other hand, the effects of an augmented secretion of natriuretic peptides from cardiac myocytes should reduce vasoconstriction and water retention. There is increasing evidence suggesting that pharmacological interventions that modify the neuroendocrine responses may significantly alter the clinical course of the underlying disease process and even improve the prognosis of patients with myocardial infarction. ${ }^{1}$

\section{Sympathetic nervous system}

There is general agreement in published work that noradrenaline concentration in circulating blood represents the spillover of far higher local concentrations of the hormone at the site of action close to the sympathetic nerve terminals and that plasma noradrenaline concentration is the best indicator of sympathetic nervous activity. Plasma concentrations of noradrenaline are raised in most patients with chronic congestive heart failure, and in this condition a high plasma noradrenaline concentration indicates a poor prognosis. $^{2}$

Previous observations have shown unequivocally that plasma catecholamine concentrations are increased early in the course of acute myocardial infarction (table). ${ }^{34}$ The increase in sympathetic tone depends on the extent of cardiac damage and the haemodynamic consequences of the infarction. In uncomplicated infarctions plasma concentrations of noradrenaline are raised to no more than five or six times the normal resting plasma value, and an increase of this size may not have a particularly deleterious effect on the circulatory system. In underperfused myocardium, however, the sensitivity to adrenergic stimuli is enhanced and, consequently, even a moderately raised circulating catecholamine concentration may be arrhythmogenic. In large and complicated infarctions pain and anxiety contribute to increased sympathetic nervous tone, and a decreased cardiac output resulting in hypotension and hypoperfusion frequently triggers a pronounced reflex increase in sympathetic nervous activity, accompanied by a far greater release of noradrenaline from the nerve endings into circulating blood. Thus, high plasma catecholamine concentrations can be detected in patients with pulmonary oedema or shock, predisposing the patients to serious arrhythmias and sudden death. ${ }^{5}$

In addition to high circulating catecholamine concentrations, local sympathetic activation may occur with exocytotic release of noradrenaline from cardiac sympathetic nerve terminals. Furthermore, during prolonged myocardial ischaemia catecholamines escape from their storage vesicles by non-exocytotic local release, which is triggered by a variety of metabolic factors. As a net result of the exocytotic and non-exocytotic release, dramatically high noradrenaline concentrations of up to 100-1000 times the normal plasma value have been detected in the extracellular space of the myocardium in animals. Catecholamine concentrations of this size are capable of causing myocardial necrosis even in the non-ischaemic segments of the myocardium. ${ }^{5}$ Recently, increased cardiac sympathetic nervous activity in response to myocardial ischaemia has been shown by measuring raised noradrenaline concentrations in coronary sinus blood of patients with unstable angina. ${ }^{6}$

Even moderately raised catecholamine concentrations after myocardial infarction may be detrimental in causing tachycardia or raised peripheral vascular resistance, thus increasing cardiac and systemic demand for oxygen. High circulating and cardiac concentrations of catecholamines also presumably have an important role in inducing ventricular tachycardias leading to sudden death and may further enhance myocardial cell necrosis.

\section{Renin-angiotensin systems}

Traditionally, the renin-angiotensin-aldosterone system refers to the neurohumoral mechanism which becomes activated through an increased secretion of renin from the kidneys. This system is promptly activated in any condition associated with renal hypoperfusion, and its activity is usually assessed by measuring plasma renin activity or plasma concentrations of angiotensin II or aldosterone. The excretion of renin from the juxtaglomerular cells is triggered by renal hypoperfusion itself, by low sodium delivery to 
Neuroendocrine activity in SAVE study (adapted from Rouleau et $\mathrm{al}^{4}$ ). ${ }^{\star}$ Values are mean (SD) concentrations

\begin{tabular}{lccc}
\hline Variable & $\begin{array}{c}\text { Control subjects } \\
(n=38)\end{array}$ & $\begin{array}{c}\text { Patients } \\
(n=335) \dagger\end{array}$ & P value \\
\hline Plasma renin $(\mathrm{ng} / \mathrm{ml} / \mathrm{h})$ & $1 \cdot 2(1 \cdot 2)$ & $2 \cdot 4(2 \cdot 9)$ & $<0.0001$ \\
Aldosterone $(\mathrm{ng} / \mathrm{dl})$ & $17(7)$ & $22(22)$ & 0.029 \\
Noradrenaline $(\mathrm{pg} / \mathrm{ml})$ & $221(87)$ & $278(173)$ & $<0.0001$ \\
Antidiuretic hormone $(\mathrm{pg} / \mathrm{ml})$ & $0 \cdot 7(0 \cdot 3)$ & $1 \cdot 6(8 \cdot 2)$ & 0.05 \\
Atrial natriuretic peptide $(\mathrm{pg} / \mathrm{ml})$ & $21(9)$ & $65(64)$ & $<0.0001$ \\
\hline
\end{tabular}

*Samples were taken a mean of 12 days after the index myocardial infarction. $\dagger$ Not taking diuretics. after infarction. A significant rise in plasma angiotensin II, renin, and arginine vasopressin concentrations has been observed even in the recovery phase of uncomplicated, though large, infarctions, with further increases in those requiring diuretic treatment (table). ${ }^{4}$ However, Vaughan et al have recently shown that plasma angiotensin II concentration may remain raised for up to three weeks after a large anterior wall infarction in clinically stable patients not treated with diuretics. ${ }^{11}$ In addition, the degree of activation of the reninangiotensin-aldosterone system may be related to the extent of left ventricular dysfunction. ${ }^{11}$

Low cardiac output resulting in diminished renal blood flow is probably the most important trigger mechanism activating the renin-angiotensin-aldosterone system after myocardial infarction; the system is activated further by an increase in renal sympathetic nerve activity. Early in the course of myocardial infarction the activation serves to maintain adequate circulation, but later an excessive activation of the compensatory mechanism may become deleterious. An excessive increase in systemic vascular resistance and a disproportionate expansion of circulating blood volume, caused by the effects of angiotensin II itself, will increase aortic impedance and volume load to the left ventricle. In addition, angiotensin II interacts with the sympathetic nervous system to induce tachycardia and to increase systemic vasomotor tone, thus increasing afterload and cardiac oxygen demand still further. Simultaneously, angiotensin II may augment myocardial ischaemia through its vasoconstrictor effect on the coronary arteries. These detrimental actions are likely to cause an additional worsening of the previously compromised pump function and may contribute to the development of overt congestive heart failure after myocardial infarction. ence suggesting that the local cardi tissue renin-angiotensin mechanism, operating within the heart independent of the circulatory renin-angiotensin-aldosterone system, may have an important function in the adaptive process after infarction. Furthermore, recent results from experimental research suggest that angiotensin II, through its local effect on cardiomyocytes, may directly enhance the secretion of atrial natriuretic peptide and, thus, activate a counterbalancing homoeostatic mechanism. ${ }^{10}$

\section{Activation of renin-angiotensin systems after myocardial infarction}

The renin-angiotensin-aldosterone system is activated in most patients with chronic congestive heart failure, and in such patients the use of diuretic treatment is an important cause of the activation. Not surprisingly, there is evidence of an increased activity of the homoeostatic system in patients recovering from myocardial infarction. Renin, angiotensin II, and aldosterone values are often raised on admission, reach their peak value on day 3 , and remain raised until day 10 in patients presenting with left ventricular failure

\section{Cardiac renin-angiotensin system and ventricular remodelling}

Recently, the term "ventricular remodelling" has been introduced to describe a series of morphological changes in the heart after myocardial infarction that eventually result in dilatation and systolic dysfunction of the ventricle. Remodelling encompasses not only the infarcted segments of the myocardium but also the surrounding non-infarcted portions of the ventricular wall. An early expansion of the infarcted segment of the myocardium may be observed within a few hours or days, particularly after large anterior infarctions, when the necrotic myocardium thins and elongates. Thereafter, within several weeks or months after the early response, global remodelling of the residual viable myocardium ensues, presumably as an attempt to maintain stroke volume. In the remodelling process side slippage of myocytes in the non-infarcted zone, resulting in an increase in cardiac volume while the thickness of the intact myocyte hypertrophy is associated with side to 
ventricular wall is maintained or even reduced. Over time an increased wall stress may then induce the development of eccentric ventricular hypertrophy. This process entails further growth of cardiac myocytes and progressive myocardial fibrosis, with rearrangement of the architecture of the extracellular matrix. Eventually, because of increased wall stress, the compensatory mechanism may fail to maintain adequate pump function and congestive heart failure ensues. ${ }^{12}$

Currently, increasing indirect evidence suggests that angiotensin II, and perhaps also aldosterone, may have important influences on the maladaptive process. At least at pharmacological concentrations, angiotensin II is capable of increasing myocardial contractility, stimulating myocardial growth, and inducing fibroblast proliferation, the latter being also enhanced by aldosterone. Such influences might contribute to myocardial hypertrophy and fibrosis during the ventricular remodelling process. ${ }^{13}$ Currently, however, results from studies directly examining the role of the cardiac renin-angiotensin system during remodelling are scarce and, hence, the exact role of the system in the remodelling process remains unresolved.

\section{Natriuretic peptides}

In the early 1980s the granules in atrial myocytes were proved to contain a polypeptide hormone, later called atrial natriuretic peptide (ANP). In healthy humans the peptide is stored as a prohormone of 126 amino acids within the atrial granules, but in patients with ventricular hypertrophy or chronic congestive heart failure it can also be found in the ventricular myocytes. In response to atrial stretching the prohormone is split by a membrane protease and released into the circulation as a bioactive $\mathrm{C}$ terminal peptide (C-ANP; 28 amino acids) and an $\mathrm{N}$ terminal peptide (N-ANP; 98 amino acids), which is assumed not to have any important biological effects. The natriuretic and diuretic effects of C-ANP are probably mediated by the kidneys, while the vasodilator effect is mediated by increasing production of cyclic guanosine monophosphate in vascular smooth muscle cells. Because of a low clearance rate, N-ANP circulates at 10 to 20 times higher concentrations than C-ANP and, because of its stability, is considered to be the most accurate indicator of release of atrial natriuretic peptide. $^{14}$

Brain natriuretic peptide is another vasoactive hormone, isolated recently from porcine brain. Subsequent studies in humans have shown that the heart is the primary source of brain natriuretic peptide and that cardiac ventricular tissue, rather than the atria, is the site of its synthesis and secretion. Hence, plasma concentrations of brain natriuretic peptide might be a more sensitive and specific indicator of alterations in ventricular function than are plasma atrial natriuretic peptide concentrations. Brain natriuretic peptide contains 32 amino acids, its structure is homologous to that of C-ANP, and the two peptides share a similar profile of diuretic, natriuretic, and vasodilator actions. ${ }^{15}$

Previous studies have shown that plasma concentrations of both C-ANP and N-ANP are raised in patients with chronic congestive heart failure and, to a lesser extent, in subjects with left ventricular dysfunction without manifest symptoms of heart failure. ${ }^{2} 314$ Furthermore, in patients with congestive heart failure, a very high C-ANP concentration in circulating blood indicates a poor prognosis. ${ }^{2}$ Increased circulating concentrations of brain natriuretic peptide have been found in patients with hypertension and left ventricular hypertrophy and in those with chronic congestive heart failure. In the latter high plasma concentrations of brain natriuretic peptide correlate with the severity of the disorder. ${ }^{15} 16$

\section{Role of natriuretic peptides after myocardial infarction}

Myocardial infarction causes an abrupt rise in the cardiac filling pressures, and the subsequent increase in atrial stretch, along with myocardial cell necrosis, enhances secretion of the natriuretic peptides. Indeed, several clinical observations have confirmed that plasma concentrations of C-ANP, $\mathrm{N}$-ANP, and brain natriuretic peptide are all raised appreciably even after uncomplicated myocardial infarctions, but the increase is far greater in patients with complicated infarctions resulting in congestive heart failure. ${ }^{17-20}$ Regardless of the presence or absence of heart failure, plasma concentrations of the natriuretic peptides seem to reflect the extent of myocardial injury caused by the infarction. This has been found in several studies showing a positive correlation between plasma concentrations of the peptides and the increase in cardiac enzyme activities or pulmonary capillary wedge pressure; a negative correlation exists between the hormone concentrations and left ventricular ejection fraction or exercise performance after infarction. ${ }^{1721}$ Furthermore, disproportionately high plasma concentrations of atrial natriuretic peptide have been observed in patients with myocardial infarction extending to the right ventricle, suggesting that the peptide may have a pathophysiological role in the clinical right ventricular infarction syndrome. ${ }^{22}$

Of the three natriuretic peptides, the rise in C-ANP concentration seems to be most abrupt after myocardial infarction. Plasma concentration of C-ANP has usually reached its peak value at the time of admission, and, in uncomplicated infarctions, it usually returns to near normal values within hours or a few days. On the other hand, plasma concentrations of $\mathrm{N}$-ANP and brain natriuretic peptide are only moderately raised on admission but continue to rise during the ensuing days, usually remaining raised for much longer than C-ANP concentrations. Plasma concentrations of the neuropeptides are related to the severity of the 
myocardial injury. In complicated infarctions leading to heart failure, plasma concentrations of C-ANP, N-ANP, and brain natriuretic peptide all remain raised for several months. Thus it is no surprise that these assessments can be used to predict the long term outcome of patients after myocardial infarction. ${ }^{23}$

\section{Endothelin-1}

Coronary blood flow is locally regulated by a variety of vasodilator and vasoconstrictor agents released from the vascular endothelium. A group of vasoconstrictor peptides known as endothelins are among these agents. At least three isoforms of endothelin have been described, each consisting of 21 amino acids and four cysteine residues, but endothelin-1 is the only circulating isoform produced by endothelial cells. Endothelin-1 exerts a strong vasoconstrictor effect on the underlying myocytes in the coronary arterial wall and can act as a mitogen in smooth muscle cells. It also has a positive inotropic effect on the heart and can inhibit renin release from the juxtaglomerular cells. Hypoxia, thrombin, and physical shear forces to the coronary artery walls increase preproendothelin gene expression and the secretion of endothelin-1, while other substances, including adenosine, may suppress its release from the coronary endothelium. ${ }^{24}$

The present role of endothelin I in vascular physiology and vascular diseases remains unresolved, but the peptide might be involved, along with many other mediators, in the pathogenesis of myocardial ischaemia and infarction. ${ }^{25}$ Indeed, raised plasma endothelin-1 concentrations have been found not only in patients with myocardial infarction but also during the acute phase of unstable angina. In patients with acute myocardial infarction plasma concentrations of endothelin-1 increase rapidly and reach a peak value approximately six hours after the onset of chest pain. When the course of the infarction is uncomplicated, plasma endothelin-1 concentrations return to the normal range within 24 hours, but in patients with complicated infarctions they may remain raised for up to one week. So far, no significant correlation has been found between plasma endothelin-1 concentration and peak creatinine kinase isoenzyme $M B$ release, but a significant inverse relation between left ventricular systolic function and plasma endothelin-1 concentration has been observed in patients with complicated infarctions leading to heart failure. ${ }^{26}$ These data suggest that in patients with myocardial infarction plasma endothelin-1 concentration may reflect continuing ischaemia or appreciable depression of ventricular function, rather than the extent of myocardial injury itself. ${ }^{27}$

\section{Clinical implications}

There is compelling evidence that drug treatment with $\beta$ adrenoceptor blocking drugs can improve survival after acute myocardial infarction, ${ }^{28}$ and recent trials have shown that mortality can be reduced and congestive heart failure prevented by the use of ACE inhibitors in patients with left ventricular dysfunction after myocardial infarction. ${ }^{1}$ The therapeutic role of newer drugs, including angiotensin II receptor blocking agents, neutral endopeptidase inhibitors (which increase concentrations of atrial and brain natriuretic peptides), and antagonists of endothelin-1, remains to be determined. On the other hand, early diagnosis in patients during the symptomless phase of heart failure has engaged growing scientific interest. There is evidence that assessment of plasma C-ANP or $\mathrm{N}$-ANP concentrations can be used as a diagnostic test in detecting patients with asymptomatic left ventricular dysfunction after myocardial infarction ${ }^{14}$ or in identifying patients with mild congestive heart failure among other patients with dyspnoeic symptoms. ${ }^{29}$ In addition, new data suggest that determination of plasma concentration of brain natriuretic peptide might be useful in identifying the patients with clinically significant left ventricular dysfunction who are most likely to benefit from long term ACE inhibition after myocardial infarction. ${ }^{30}$ Thus, excessive neuroendocrine activation after myocardial infarction is not only an important pathophysiological target for therapeutic interventions but also contributes potentially useful diagnostic approaches.

1 Pfeffer MA, Braunwald E, Moye LA, Basta L, Brown EJ Jr, et al. Effect of captopril on mortality and morbidity in patients with left ventricular dysfunction after myocardial infarction. N Engl f Med 1992;327:669-77.

2 Swedberg K, Eneroth P, Kjekshus J, Wilhelmsen L. Hormones regulating cardiovascular function in patients with severe congestive heart failure and their relation to mortality. Circulation 1990;82:1730-6.

3 McAlpine HM, Morton JJ, Leckie B, Rumley A, Gillen G, Dargie J. Neuroendocrine activation after acute myocardial infarction. Br Heart $¥$ 1988;60:117-24

4 Rouleau JL, deChamplain J, Klein M, Bichet D, Moye L, et al. Activation of neurohormonal systems in postinfarction left ventricular dysfunction. $\mathcal{f} \mathrm{Am}$ Coll Cardiol infarction left vent

5 Schömig A. Catecholamines in myocardial infarction. Circulation 1990;82(suppl II): 13-22.

6 McCance AJ, Thompson PA, Forfar JC. Increased cardiac sympathetic activity in patients with unstable coronary sympathetic activity in patients with unst

7 Lindpaintner K, Ganten D. The cardiac renin-angiotensin Lindpaintner K, Ganten D. The cardiac renin-angiotensin
system. An appraisal of present experimental and clinical system. An appraisal of present experin
evidence. Circ Res 1991;68:905-21.

8 Morgan K, Wharton J, Webb J, Davis G, Keogh B, Smith PLC, et al. Expression of angiotensin, renin and angiotensin converting enzyme genes in human atrial tissue. Br Heart f 1993;69:P22

9 Morgan K, Wharton J, Webb J, Keogh BF, Smith PLC, Taylor KM, et al. Co-expression of renin-angiotensin system component genes in human atrial tissue. $f$ Hypertens 1994;12(suppl 4) (in press)

10 Focaccio A, Volpe M, Ambrosio G, Lembo G, Pannain S, et al. Angiotensin II directly stimulates release of atrial natriuretic factor in isolated rabbit hearts. Circulation 1993;87:192-8.

11 Vaughan DE, Lamas GA, Pfeffer MA. Role of left ventricular dysfunction in selective neurohumoral activation in the recovery phase of anterior wall acute myocardial infarction. Am f Cardiol 1990;66:529-32.

12 Pfeffer MA, Braunwald E. Ventricular remodelling after myocardial infarction. Circulation 1990;81:1161-72.

myocardial infarction. Circulation 1990;81:1161-72.
13 Lindpaintner K, Niedermaier N, Drexler H, Ganten D. Left ventricular remodelling after myocardial infarction: Left ventricular remodelling after myocardial infarction:
does the cardiac renin-angiotensin system play a role? $f$ does the cardiac renin-angiotensin system $\mathrm{p}$

14 Lerman A, Gibbons RJ, Rodeheffer RJ, Bailey KR, McKinley LJ, Heublein DM, et al. Circulating -terminal atrial natriuretic peptide as a marker of sympt105-9. 
15 Mukoyama M, Nakao K, Saito Y, Ogawara Y, Hosoda K, et al. Increased human brain natriuretic peptide in

16 Kohno M, Horio T, Yokokawa K, Murakawa K, Yasunari $\mathrm{K}$, et al. Brain natriuretic peptide as a cardiac hormone in et al. Brain natriuretic peptide as a cardiac horm

17 Tomoda H. Atrial natriuretic peptide in acute myocardial infarction. Am $\mathcal{f}$ Cardiol 1988;62:1122-3.

18 Fontana F, Bernardi P, Spagnolo N, Capelli M. Plasma atrial natriuretic factor in patients with acute myocardial infarction. Eur Heart f 1990;11:779-87.

19 Ngo L, Veseley DL, Bissett KJ, Murphy ML, Dinh HA, et al. Acute and sustained release of the atrial natriuretic factor prohormone $\mathrm{N}$-terminus with acute myocardial infarction. Am F Med Sci 1991;301:157-64.

20 Morita E, Yasue $H$, Yoshimura M, Ogawa $H$, Jougasaki $M$, et al. Increased plasma levels of brain natriuretic peptide in patients with acute myocardial infarction. Circulation 1993;88:82-91.

21 Omland T, Bonarjee VVS, Aakvaag A, Aarsland T, Dickstein $\mathrm{K}$. The relationship between early plasma atrial natriuretic factor levels and exercise performance after myocardial infarction. Eur Heart $f$ 1993;14:1022-6.

22 Robalino BD, Petrella RW, Jubran FY, Bravo EL, Healy $\mathrm{BP}$, et al. Atrial natriuretic factor in patients with right ventricular infarction. $\mathcal{f} \mathrm{Am}$ Coll Cardiol 1990;15: 546-53.

23 Hall C, Rouleau JL, Klein M, Sussex B, Packer M, et al. $\mathrm{N}$-terminal natriuretic factor (PRO-ANP) - a uniquely powerful predictor of long term outcome after myocardial infarction [abstract]. $\mathcal{f} \mathrm{Am}$ Coll Cardiol 1993;21:270A.

24 Lechleitner P, Genser N, Mair J, Maier J, Artner-Dworzak $\mathrm{E}$, et al. Plasma immunoreactive endothelin in acute and $E$, et al. Plasma immunoreactive endothelin in acute and subacute phases of myocardial infarction in patients undergoing fibrinolysis. Clin Chem 1993;39:955-9.

25 Stewart DJ, Kubac GK, Costello KB, Cernacek P. Increased plasma endothelin-1 in the early hours of acute myocardial infarction. I Am Coll Cardiol 1991;18: 26 Lechleitner.

Lechleitner P, Genser N, Mair J, Maier J, Artner-Dworzak $\mathrm{E}$, et al. Endothelin-1 in patients with complicated and uncomplicated myocardial infarction. Clin Invest 1992;70:1070-2.

27 Tomoda H. Plasma endothelin- 1 in acute myocardial infarction with heart failure. Am Heart $f$ 1993;125: 667-72.

28 Yusuf S, Peto R, Lewis J, Collins S, Sleight P. Betablockade during and after myocardial infarction. An overview of the randomized trials. Prog Cardiovasc Dis 1985;27:335-71.

29 Remes J, Tikkanen I, Fyhrquist F, Pyörälä K. Neuroendocrine activity in untreated heart failure. $\mathrm{Br}$ Heart $\mathrm{f}$ 1991;65:249-55.

30 Motwani JG, McAlpine H, Kennedy D, Struthers AD. Plasma brain natriuretic peptide as an indicator for angiotensin-converting-enzyme inhibition after myoangiotensin-converting-enzyme inhibition
cardial infarction. Lancet 1993;341:1109-13. 